\title{
EL CICLO EVOLUTIVO EXPERIMENTAL DE Diphyllobothrium erinaceieuropei EN Paracyclops fimbriatus, LARVAS DE Bufo arenarum Y CANINOS
}

\author{
Lucila VENTURINI (1)
}

\section{RESUMEN}

El objetivo del trabajo fue lograr la reproducción experimental del ciclo evolutivo de Diphyllobothrium erinaceieuropei Rudolphi 1819 (Cestoda, Pseudophyllidea) con la intervención de Paracyclops fimbriatus y larvas de Bufo arenarum como hospedadores intermediarios y caninos como hospedadores definitivos.

Los huevos del parásito se obtuvieron de heces de caninos infectados naturalmente y se conservaron refrigerados en agua. Se incubaron 7 días a $25 \mathrm{C}$ para que desarrollaran los coracidios y se pusieron en recipientes que contenian a los copépodos mencionados. Al cabo de 12 dias a $22,6^{\circ} \mathrm{C}$ (promediol se hallaron procercoides maduros en ellos y se agregaron 10 renacuajos de $\mathbf{B u f o}$ arenarum. Estos se examinaron por disección 22,23, 61 y 107 días después, hallándose en todos 1 o más plerocercoides (Temperatura promedio: 24,9 "C).

El día 23, de 6 renacuajos se obtuvieron 49 plerocercoides, de los cuales se administraron 28, por vía oral, a una perra. El dia 107, 3 de 11 plerocercoides obtenidos de un renacuajo se le dieron a otra perra por la misma vía.

Se hallaron huevos del cestode en las heces del primer canino a partir del día 22 posterior a la infección (p.i.) y a los 30 días p.i., segmentos de estróbila. En el segundo canino se hallaron huevos a los 30 días p.i..

UNITERMOS: Diphyllobothrium erinaceieuropei, ciclo evolutivo, Cestodes, evolu ción experimental.

\section{INTRODUCCIÓN}

Diphyllobothrium erinaceieuropei Rudolphi 1819 (Cestoda, Pseudophyllidea), en estado aduito parasita el intestino de cánidos, félidos y seres humanos 2.3 .6 a 8, 12, 15. Este parásito ha sido hallado en Sudamérica ${ }^{13,15}$ pero no se logró reproducir el ciclo evolutivo completo. Sólo se han obtenido cestodes adultos en caninos a los que se le administraron plerocercoides extraídos de animales infectados naturalmente ${ }^{15}$.
Durante dicho ciclo evolutivo, los huevos son expulsados al exterior con las heces. Si van al agua, desarrolla en su interior un coracidio, el cúal, al ser ingerido por un crustáceo copépodo, continúa su evolución hasta el estado de procercoide $^{1 \text { a 3.7a } 9}$. Para llegar al estado de plerocercoide debe ser comido por batracios, reptiles, aves o mamíferos ${ }^{1}$ a 9.14.15. Este estado, también llamado espargano, produce un factor de creci

1) Profesora Titular de Parasitolonia y Enfermedades Parasitarias de la Facultad de Ciencias Veterinarias de la Universidad Nacional de La Plata. Argentina. Investigador del Consejo Nacional de Investigaciones Científicas y Técnicas. 
VENTURINI. L - El ciclo evolutivo experimental de Diphyllobothrium erinaceieuropei en Paracyclops fimbriatus, larvas de Bufo arenarum y caninos. Rev. Inst. Med. trop. S. Paulo, 31(5): 308 312, 1989.

miento en sus hospedadores intermediarios ${ }^{11}$. Si es ingerido por cánidos o félidos se desarrolla el estado adulto en el intestino. En seres huma nos se pueden hallar plerocercoides o adultos ${ }^{6}$ 12.

Según algunos autores. ${ }^{1.3 .9}$, las larvas de batracios serían los hospedadores más adecuados para que se produzca la evolución de procercoide a plerocercoide. Los batracios adultos y los animales de los otros grupos zoológicos antes mencionados actuarian como hospedadores de transporte, adquiriendo la infección por la inges ta de renacuajos.

El objetivo de este trabajo fue lograr la reproducción experimental del ciclo evolutivo de Diphyllobothrium erinaceieuropei con la intervención de Paracyclops fimbriatus y larvas de Bufo arenarum como hospedadores intermedia rios y caninos como hospedadores definitivos.

\section{MATERIALES Y METODOS}

Se lavó la materia fecal de caninos natural mente infectados por Diphyllobothrium erinaceieuropei, a traves de tamices de distinta medi$\mathrm{da}$, reteniendo los huevos con uno de 400 meshes. Se conservaron en refrigerador a $5^{\circ} \mathrm{C}$ en agua destilada. Para obtener coracidios, los huevos se pusieron en estufa a $25^{\circ} \mathrm{C}$, durante 7 días.

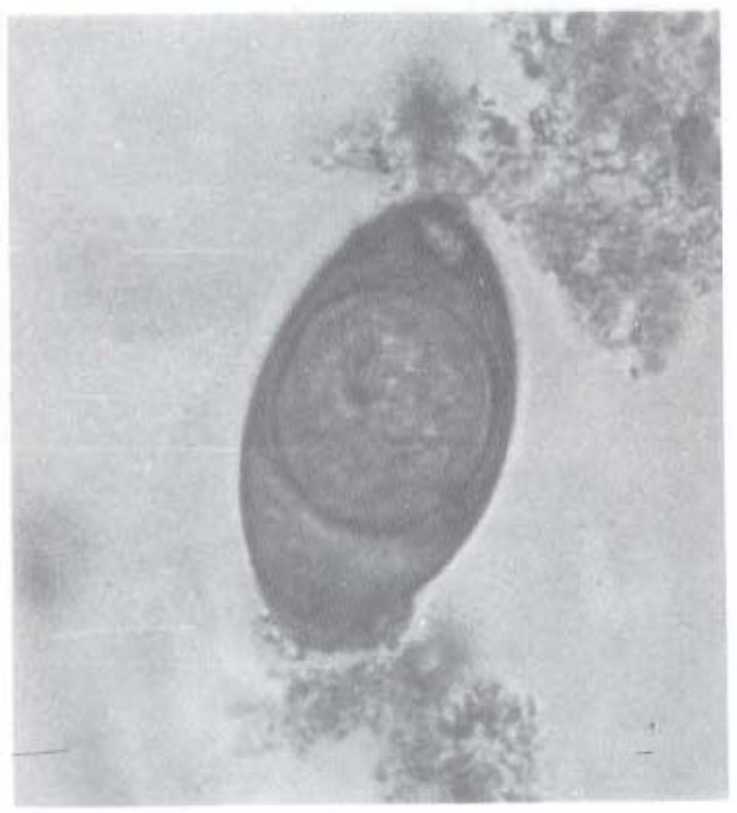

Se tomaron muestras de agua que contenian copépodos, de una charca permanente: pertene cían a la especie Paracyclops fimbriatus. Se mantuvieron en el laboratorio en recipientes de vidrio, con iluminación natural.

Se examinaron microscópicamente, en fres co, 100 individuos, determinándose que no esta. ban infectados.

Se colectaron renacuajos de Bufo arenarum y se mantuvieron en recipientes con agua cor riente, agregando a los mismos, periódicamente. hojas de lechuga como alimento.

Para lograr el desarrollo del cestode adulto se mantuvieron en cautiverio 2 perras. una de 3 años de edad ( $N$ : 1) y la otra de 3 meses ( $N$. 2), libres de infección previa por Diphyllobothrium erinaceieuropei.

Los perros de los cuales se obtuvieron los huevos del parásito, así como los renacuajos y los copépodos eran de la ciudad de La Plata (Ar gentina).

Se pusieron coracidios en los recipientes que contenían a los copépodos. Se extrajeron 3 a 5 ejemplares diariamente, se observaron micros cópicamente, en fresco, a fin de apreciar la evolu ción de la infección y se midieron las formas parásitas halladas.

Se pusieron 10 renacuajos en un recipiente que contenía copépodos con procercoides madu ros. Veintidós, 23, 61 y 107 días después, se exa. minaron $1,6,2$ y 1 renacuajo, respectivamente mediante disección bajo lupa estereoscópica Los primeros 7 renacuajos se mataron para ins peccionarlos, los 3 últimos murieron espontá neamente.

Se mantuvieron 40 renacuajos como testigos en recipientes sin copépodos, 20 se examinaron al comienzo del experimento y 20 mas entre los días 23: y 61\%. Se midieron en vivo los plerocer coides obtenidos los días 23,61 y 107 . Se registró la temperatura del laboratorio.

Se adminis traron a la perra N". 1, por vía oral, 28 plerocercoides obtenidos durante la disección de renacuajos del dia 23 y a la perra No 2 ; 3 plero cercoides del día 107. 
VENTURINI, L - El ciclo evolutivo experimental de Diphyllobothrium erinaceieuropei en Paracyclops fimbriatus, larvas de Bufo arenarum y caninos. Rev. Inst. Med. trop. S. Paulo, 31(5): 308 312, 1989

Se realizaron exámenes de materia fecal de los caninos por la técnica de Benbrooke modifi cada (flotación de huevos de helmintos en solución de azúcar de 1300 de densidad, por centrifugación), a partir de los días 10: y 30: posteriores a la administración de plerocercoides (perra $\mathrm{N}$ : 1 y N: 2 , respectivamentel.

Se fotografiaron los estados del cestode. los plerocercoides y los segmentos de la estróbila se tineron con carmín clorhidrico y se diafanizaron con creosota.

\section{RESULTADOS}

Las formas de desarrollo del parásito halla das en los copépodos que estuvieron con coraci dios, fueron las siguientes:

a) esféricas, de 39 a 45 micrómetros de diámetro, con tres pares de ganchos;

b) elipsoidales, de 66 a 117 micrómetros de lárgo por 27 a 45 de diámetro, con los ganchos en un extremo:

c) elipsoidales, con cércómero, de hasta $193 \mathrm{mi}$. crómetros de largo por 66 de diámetro:

d) elipsoidales, sin cercómero, de 132 micrómetros de largo por 57 de diámetro, con espinas bien desarrolladas en la extremidad anterior y corpúsculos calcáreos. Esta última forma se consideró procercoide infectante.

El tiempo mínimo transcurrido, desde que se pusieron los coracidios hasta que se hallaron los procercoides completamente desarrollados, fue de 12 días, a $22,6^{\circ} \mathbf{C}$ de temperatura promedio $\left(20^{\circ}\right.$ a $\left.25^{\circ} \mathrm{C}\right)$.

En la Figura n: 4 se hallan los resultados de la infección de los renacuajos.

El plerocercoide del día 22: midió $2,7 \mathrm{~mm}$. Los de los dias 61 y 107 alcanzaron $\operatorname{los} 5 \mathrm{~mm}$. Algunos plerocercoides abandonaron los rena. cuajos muertos. La temperatura promedio para los 107 días fue de $24,9^{\prime \prime} \mathrm{C}$ (21" a $31^{\circ} \mathrm{C}$ ).

No se hallaron plerocercoides en los renacuajos testigos.

En las heces de la perra N: 1, se hallaron huevos del parásito desde el dia 22 posterior a la administración de plerocercoides hasta el día 44". y a partir del día 134". En el lapso comprendido entre los días 50: y 130 , no se observaron

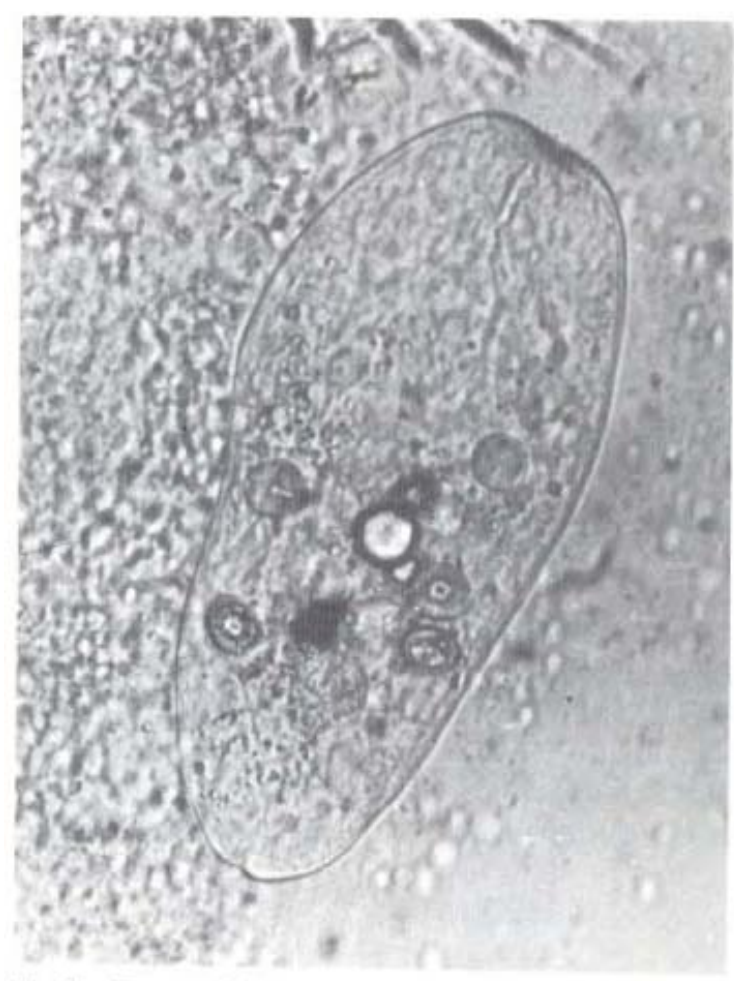

Fig. 2 - Procereolde.

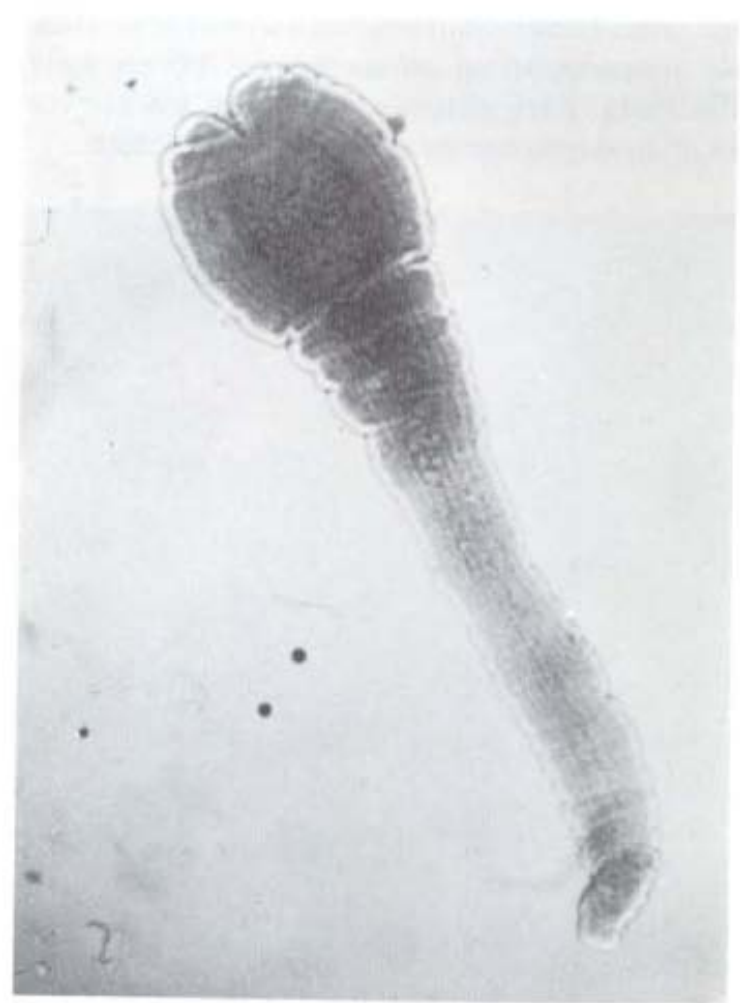

Fig. 3-Plerocercoide. 
VENTURINI. L - El ciclo evolutivo experimental de Diphyllobothrium erinaceieuropei en Paracyclops fimbriatus, larvas de Bufo arenarum y caninos. Rev. Inst. Med. trop. S. Paulo, 31(5): $308312,1989$.

\begin{tabular}{|r|c|c|}
\hline Dia: & cantidad de renacuajos & $\begin{array}{c}\text { cantidad de pleroccrcoides } \\
\text { por renacuajo }\end{array}$ \\
\hline 22. & 1 & 1 \\
$23:$ & 6 & $2,4,7,9,13,14$ \\
$61:$ & 2 & 5,2 \\
107. & 1 & 11 \\
\hline
\end{tabular}

Dia: corresponde al día en que fueron examinados los rena cuajos después de haberlos puesto con los copépodos infec tados.

Fig. 4-Plerocercoides obtenidos de larvas de Bufo arenarum.

huevos del parásito. En las heces de la perra N. 2 se hallaron huevos a partir del día $30 \%$

Treinta días después de la infección de la perra N". 1, se hallaron segmentos de estróbila en su materia fecal. Las características morfológicas correspondieron con las de Diphyllobothrium erinaceieurope $i^{2,6,10}$.

\section{DISCUSIÓN}

Se logró la reproducción experimental del ciclo evolutivo de Diphyllobothrium erinaceieuropei con la intervención de Paracyclops fimbriatus y larvas de $B$ ufo arenarum como hospedadores intermediarios y caninos como hospe dadores definitivos.

Varios autores comprobaron que el desarrollo de los procercoides se realiza en copépodos de la familia Cyclopidae ${ }^{1,2.3 .7 .8}$. Aunque existen diferencias de susceptibilidad a la infección ${ }^{1}, 3$. ${ }^{8}$, no se ha hallado ninguna especie que sea absotutamente refractaria, por lo que es probable que otras especies de la misma familia, además de Paracyclops fimbriatus, actúen como primer hospedador intermediario en Sudamérica.

Según algunos de los autores antes citados, la evolución hasta el estado de plerocercoide se produce en renacuajos de ranas, como Hyla latopalmata ${ }^{9}$, Rana tigrina, Rana limnocharis y $R \mathbf{a -}$ na ghenteri ${ }^{3}$, y de Crinia $s^{1}$.

En este experimento el estado de plerocercoide fue alcanzado en renacuajos del sapo $\mathbf{B u f o}$ arenarum.

Los plerocercoides obtenidos de renacuajos vivos y muertos fueron infectantes para las per- ras, algunos abandonaron espontáneamente los renacuajos muertos, hecho que ya fuera obser vado anteriormente ${ }^{3}$.

La susceptibilidad a la infección evidencia da por los renacuajos de $\mathbf{B u f o}$ arenarum justifica la suposición de que actúen como segundo hos pedador intermediario en el ciclo natural del pa. rásito.

Los hospedadores definitivos y los de transporte podrian infectarse por predación de los mismos, pero también al abrevar en charcas, por la ingesta de renacuajos vivos o muertos, o de plerocercoides libres. La infección accidental podría ser de importancia en la transmisión de la parasitosis, no quedando esta restringida a las relaciones predator-presa.

Es posible que Bufo arenarum por su adaptabilidad a distintos ambientes y por su amplia distribución intervenga en ciclos domésticos y silvestres.

Es probable que larvas de otras especies de batracios intervengan en el ciclo evolutivo de Diphyllobothrium erinaceieuropei en Sudamérica.

El desarrollo del ciclo evolutivo completo de este cestode, con la participación de hospedadores intermediarios que habitan esta región, abre un nuevo panorama para el estudio de aspectos epidemiológicos y experimentales de esta parasitosis.

\section{SUMMARY}

EXPERIMENTAL LIFE CYCLE OF Diphyllo bothrium erinaceieuropei IN Paracyclops fimbria tus, TADPOLES OF Bufo arenarum AND DOGS.

Experiments were performed in order to develop the life cycle of Diphyllobothrium erinaceieuropei Rudolphi 1819 (Cestoda, Pseudophyllidea) in Paracyclops fimbriatus and Bufo arenarum as intermediate hosts and dogs as definitive hosts

The eggs of Diphyllobothrium erinaceieuropei from faeces of naturally infected dogs were kept refrigered, in water. In order to obtain coracidiums they were incubated at $25^{\circ} \mathrm{C}$, and then 
VENTURINI. L - El ciclo evolutivo experimental de Diphyllobothrium erinaceieuropei en Paracyclops fimbriatus, larvas de Bufo arenarum y caninos. Rev. Inst. Med. trop. S. Paulo, 31(5): 308-312, 1989.

were placed in a flask which contained Paracyclops fimbriatus. The copepods were observed to be infected with procercoids 12 days after, (mean temperature $22.6^{\circ} \mathrm{C}$ ) and then, ten tadpo les of Bufo arenarum were put into the same flask.

The tadpoles were examined 22,23,61 and 107 days later, finding plerocercoids in all them (mean temperature $24.9^{\circ} \mathrm{C}$ )

On the $23^{\text {th }}$ day, 49 plerocercoids were removed from 6 tadpoles and 28 of them were fed to a bitch. On the $107^{\text {th }}$ day, 11 plerocercoids were recovered from a dead tadpole and 3 of them were fed to another bitch.

In the faeces of the first bitch there were observed the eggs of Diphyllobothrium erinaceieuropei 22 days post infection (d.p.i.) and part of the strobila 30 d.p.i. In the faeces of the second bitch the eggs were found 30 d.p.i..

\section{AGRADECIMIENTOS}

A la Dra M. L. Vigneu por su colaboración durante la elaboración del manuscrito. A la Dra P. Battistone y al Dr A. Ker, del Instituto de Limnología (Facultad de Ciencias Naturales y Museo, U.N.L.P.), que clasificaron los copépodos y las larvas de batracio, respectivamente.

\section{REFERENCIAS BIBLIOGRÁFICAS}

1. BEARUP, A. J. - Life history of a spirometrid tapeworm causing sparganosis in feral pigs. Aust. Vet. J., 29: $217-224$. 1953.

2. FAUST, E. C.; CAMPBELL, H. E. \& KELlOG, C. R. Morphological and biological studies on the species of Diphyllobothrium in China. Amer. J. Hyg., 9: 561-583, 1929.
3. GALliaRD, H. \& NGU, D. V. -.- Particularités du cycle evolutif des D. mansoni au Tonkin. Ann. Parasit. hum. comp., 21: 246-253, 1946

4. GALLIARD, H. -- Infestacion naturelle des batraciens et reptiles par les larves plerocercoides de $D$. mansoni au Tonkin. Ann. Parasit. hum. comp., 23: 23.26. 1948

5. GALLIARD, H. - Infestacion experimentale par les lar ves plerocercoides de D. mansoni au Tonkin. Ann. Parasit. hum. comp., 23: $203213,1948$.

6. IWATA, S. - Some experimental and morphological stu dies on the post embrional development of Manson's tape worm Diphyllobothrium erinacei (Rudolphi). Jap. J. Zool., 5: 209 247, 1933.

7. JOYEUX, C.: HOUDEMER, E. \& BAER, J. - Recherches sur la biologie des sparganum et l'etiologie de la sparga nose oculaire. Bull. Soc. Path. exot., $27: 70.78,1934$.

8. LI, H. C. - The life histories of Diphyllobothrium decipiens and I. erinacei. Amer. J. Hyg., 10: 527550,1929

9. SANDARS, D. F. - A study of Diphyllobothridae (Cesto da) from Australian hosts. Proc. roy. Soc. Queensland, 63: $65-70,1953$

10. SCHMIDT, G. - CRC handbook of tapeworm identification. Boca Ratón, Florida, CRC Press, 1986.

11. SHIWAKU, K. \& HIRAI, K. - Growth promoting effect of Spirometra erinacei (Rudolphi 1819 ) plerocercoids in young mice. Jap. J. Parasit., 31: 185-195, 1982.

12. SUZUKI, N \& KUMAZAWA. H. - A case of human infec tion with the adult of Spirometra erinacei ( $R$ udolphi 1819) Jap. J. Parasit., 31: 23-26, 1982

13. VENTURINI, L. - Spirometra erinacei en perro. Rev. Med. vet. (B. Aires), 61: 330-334, 1980

14. VOGELSANG, E. G. - Presencia de un Sparganum en las ranas (Leptodactylus ocellatus) del Uruguay. Rev. Med. vet. (Montevideo), 8: 301, 1925.

15. WOLFHUGEL, K. \& VOGELSANG, E. G. - Dibothricephalus decipiens (Diesing) y su larva Sparganum reptans en el Uruguay. Rev. Med. vet. (Montevideo). 9: 433-434. 1926.

Recebido para publicaçào em 28/3/1989 